\title{
Effectiveness of UVC, Ozone and Negative Ions against Bacteria and Viruses
}

\author{
Ruwan Bolongho ${ }^{1}$, Shan Dabarera ${ }^{2,}$ Sameen Perera ${ }^{3}$, Anuradha Amarasinghe ${ }^{4}$ \\ ${ }^{1}$ Research and Development Unit, Sri Lanka Navy \\ ${ }^{2}$ Research and Development Unit, Sri Lanka Navy \\ ${ }^{3}$ Research and Development Unit, Sri Lanka Navy \\ ${ }^{4}$ Research and Development Unit, Sri Lanka Navy
}

\begin{abstract}
Since the beginning of time, viruses and bacteria have been a part of human life. Several types of sterilization systems were used to disinfect these viruses and bacteria all over the world. These methods were varied according to ethnics. With the advancement of technology, people used to find new disinfection methods. Ultraviolet, Ozone, Negative Ions were some of those methods that were used to disinfect bacteria and viruses. Most of the disinfector units, use one of the above-mentioned methods for disinfection. The aim is to carry out various experiments using ultraviolet light, ozone, and ionization under different environmental conditions to measure the efficiency of these disinfection methods
\end{abstract}

Keywords - Disinfection, Negative Ions, Ozone, Ultraviolet

\section{INTRODUCTION}

With the emergence of the COVID outbreak, discussions regarding viruses and bacteria resurfaced as a hot topic around the world. Various parties are already in the process of introducing various methods of disinfection to the masses in order to achieve their own goals. Many people fail to understand that many of these products are substandard because viruses and bacteria are invisible to the naked eye. Therefore, the consumer is accustomed to accepting the product issuedby the product as it is because the proper standardization criteria have not yet been implemented in those countries. Ultraviolet light, ozone and negative ions have long been used by various parties for disinfection and have yielded positive results. However, how these approaches react to viruses and bacteria is a result that has yet to be widely publicized. As a result, we hope to conduct research into how these three disinfection approaches react to viruses and bacteria in different environments. The majority of disinfectants employ one or both of the mechanisms listed above. The combination of the three procedures is used to determine the disinfection process' success. To accomplish so, first designed a disinfection machine that incorporates all three ways. These three modes can be activated at different times and at different times, according to the device's design. As a result, this technology will make conducting this research much easier.

\section{METHODOLOGY}

The equipment was designed using the following disinfection methods.

- Ultra Violet type C disinfection

- Ozone disinfection

- Air Purification Using Negative Ion

\section{A. Ultraviolet Radiation}

Over the last few decades, UV-based disinfection has become a popular chemical- free method. UV light is extremely effective at inhibiting microbial development in any media, including water and air, as well as on any 
surface [1]. UV radiation with a wavelength range of 200 to $280 \mathrm{~nm}$, known as the UVC spectrum, has been widely used as a germicidal range of UV radiation. Because the intercellular components of microorganisms (e.g., RNA, DNA, and proteins) can sensitively absorb UVC photons, the UVC range has a more negative effect on microbial cells [2].

\section{B. Ozone disinfection}

For many years, ozone has been used to disinfect a variety of applications, including drinking water. The European Chemical Agency (ECHA), the Centers for Disease Control and Prevention (CDC), the Food and Drug Administration (FDA), the United States Environmental Protection Agency (US-EPA), and the International Ozone Association all confirm that ozone can inactivate many viruses, though none of them are aware of specific research on SARS-CoV-2. Ozone, an allotropic form of oxygen, is an inorganic gas made up of three oxygen atoms (O3) organized in a bent shape with a distance of 1.26 between them. It decomposes quickly into oxygen $(\mathrm{O} 2)$ and a single, highly reactive oxygen atom. [3][4].

\section{Negative Ion Disinfection}

Indoor air quality (IAQ) is one of the top five health concerns in the environment. HHeating ventilation and Air Conditioning (HVAC) systems are critical in ensuring the quality of the interior air in such locations. The importance of effective disinfection in ventilation systems to prevent extensive infections in- side a building has been highlighted by outbreaks of severe infectious diseases, ranging from severe acute respiratory syndrome in 2003 to avian influenza and Middle East respiratory syndrome in recent years.

The reaction of negatively and positively charged ions causes air ionization. The ions bind to airborne pathogens like viruses, creating a chemical reaction on the surface of the cell membrane. This renders the viruses inactive, rendering them incapable of spreading or causing infection. The negative ion disinfector will be the PK-A22F Airborne Negative Ion Anion Generator Module.

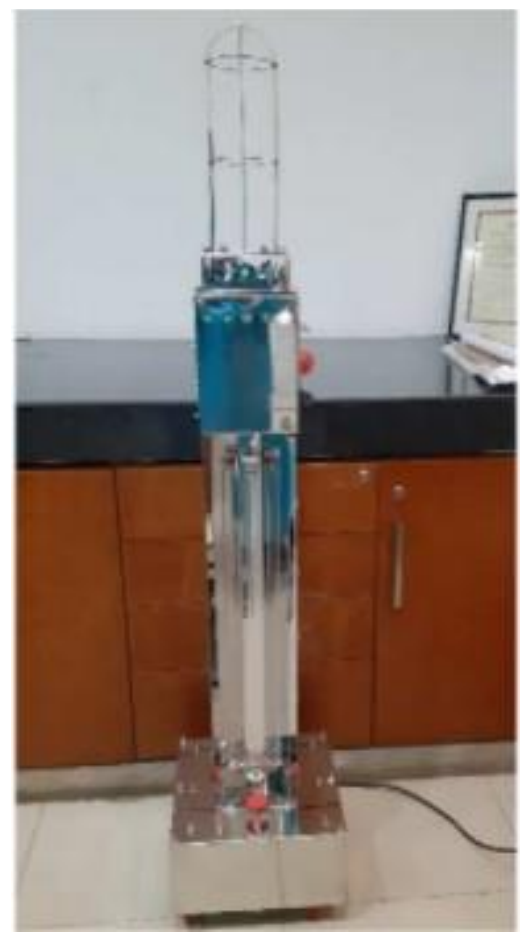

Figure 1:Designed multi disinfection system 
Test 01

- Switch on the unit.

- Turn on UVC. UVC will activate for 30 mins (10 mins on, then 2 mins off, 3 cycles will be conducted).

- Place one Sample at 1m distance from the UVC source. Sample must be placed horizontally.

- Place another Sample at a $5 \mathrm{~m}$ distance from the UVC source.

- Analyze the Sample after 30 mins.

Test 02

- Switch on the unit.

- Turn on UVC. UVC will activate for 30 mins (10 mins on, then 2 mins off, 3 cycles will be conducted).

- Place one Sample at $1 \mathrm{~m}$ distance from the UVC source. Sample must be placed vertically.

- Place another Sample at a $5 \mathrm{~m}$ distance from the UVC source.

- Analyze the Sample after 30 mins.

Test 03

- Switch on the unit.

- Turn on Ozone. Ozone will activate for 30 mins (10 mins on, then 2 mins off, 3 cycles will be conducted).

- Place one Sample at $1 \mathrm{~m}$ distance from the Ozone source. Sample must be placed vertically.

- Place another Sample at a $5 \mathrm{~m}$ distance from the Ozone source.

- Analyze the Sample after 30 mins.

\section{Test 04}

- Switch on the unit.

- Turn on both UVC and Ozone.

- Both UVC and Ozone will activate for 30 mins (10 mins on, then 2 mins off, 3 cycles will be conducted).

- Place one Sample at $1 \mathrm{~m}$ distance from the Ozone source. Sample must be placed Horizontally.

- Place another Sample at a $5 \mathrm{~m}$ distance from the UVC, Ozone source.

- Analyze the Sample after 30 mins.

Test 05

- Switch on the unit.

- Turn on both UVC and Ozone. Both UVC and Ozone will activate for 30 mins (10 mins on, then 2 mins off, 3 cycles will be conducted).

- Place one Sample at $1 \mathrm{~m}$ distance from the Ozone source. Sample must be placed Vertically.

- Place another Sample at a $5 \mathrm{~m}$ distance from the UVC, Ozone source.

- Analyze the Sample after 30 mins.

During the laboratory test, Negative Ion will always be used. The above- mentioned operations will be carried out in a variety of environmental situations, including daytime, nighttime, various humidity, pressure, and temperature conditions, as well as in a dry and wet environment.

\section{RESULTS}

Results are still awaiting, and more testing has to be conducted for an accurate conclusion. 


\section{DISCUSSION}

This study intends to make conclusions on the efficacy of the three disinfection procedures stated above, as well as to broaden the scope of the experiments and the settings in which they are conducted. It might be identified the effectiveness of direct expose of UVC rays by placing the bacteria sample in the vertical and horizontal planes. Most probably disinfection rate may be varied in various environmental conditions. Due to the detrimental effects of ozone, it's also necessary to keep track of how long it takes for the premises to become ozone depleted again following disinfection. Various environmental factors are also predicted to have an impact on this.

\section{CONCLUSION}

The disinfection process, which has been going on for a long time, began to take off with the advent of technology. Although many parties tried to carry out this process using modern methods, over time, non-standard products began to enter the society. The golis to conduct various experiments involving ultraviolet light, ozone, and ionization under various environmental conditions in order to assess the efficacy of these disinfection methods. All of these tests are designed to build a disinfection system that is safe for the customer's health.

\section{REFERENCE}

[1]. Liang, J.-J., Liao, C.-C., Chang, C.-S., Lee, C.-Y., Chen, S.-Y., Huang, S.-B., Yeh, Y.-F., Singh, K. J., Kuo, H.-C., Lin, Y.-L., \& Lu, K.-M. (2021). The Effectiveness of Far-Ultraviolet (UVC) Light Prototype Devices with Different Wavelengths on Disinfecting SARS-CoV-2. Applied Sciences 2021, Vol. 11, Page 10661, 11(22), 10661. https://doi.org/10.3390/APP112210661

[2]. Gupta, H., Kaur, H., Mahajan, P., \& Singh, G. (2021). An Insight on UVC Disinfection and COVID-19 Corresponding Author*. Medical Reports and Case Studies, 06, 223.

[3]. Galdeano, M. C., Wilhelm, A. E., Goulart, I. B., Tonon, R. V., Freitas- Silva, O., Germani, R., \& Chávez, D. W. H. (2018). Effect of water temper- ature and $\mathrm{pH}$ on the concentration and time of ozone saturation. Brazilian Journal of Food Technology, 21. https://doi.org/10.1590/1981-6723.15617

[4]. Grignani, E., Mansi, A., Cabella, R., Castellano, P., Tirabasso, A., Sisto, R., Spagnoli, M., Fabrizi, G., Frigerio, F., \& Tranfo, G. (2020). Safe and Effective Use of Ozone as Air and Surface Disinfectant in the Conjuncture of Covid-19. Gases, 1(1), 19-32. https://doi.org/10.3390/gases1010002

[5] Heating, Ventilation and Air Conditioning Systems (HVAC) Coronavirus FAQs. (2021). UVA FACILITIES MANAGEMENT. https://www.fm.virginia. edu 
